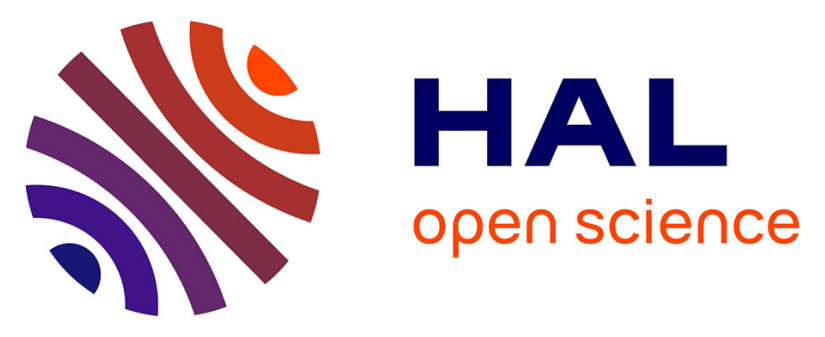

\title{
MyoNeuroGastroIntestinal Encephalopathy: Natural History and Means for Early Diagnosis
}

\author{
Giovanni Corazza, Cécile Pagan, Gaëlle Hardy, Gérard Besson, Anne Lombès, \\ David Seguy, Cécile Acquaviva-Bourdain, Francoise Bouhour, Pauline \\ Gaignard, Abdelhamid Slama, et al.
}

\section{To cite this version:}

Giovanni Corazza, Cécile Pagan, Gaëlle Hardy, Gérard Besson, Anne Lombès, et al.. MyoNeuroGastroIntestinal Encephalopathy: Natural History and Means for Early Diagnosis. Gastroenterology, 2019, 156, pp.1525 - 1527.e4. 10.1053/j.gastro.2018.12.011 . hal-03486786

\section{HAL Id: hal-03486786 https://hal.science/hal-03486786}

Submitted on 20 Dec 2021

HAL is a multi-disciplinary open access archive for the deposit and dissemination of scientific research documents, whether they are published or not. The documents may come from teaching and research institutions in France or abroad, or from public or private research centers.
L'archive ouverte pluridisciplinaire HAL, est destinée au dépôt et à la diffusion de documents scientifiques de niveau recherche, publiés ou non, émanant des établissements d'enseignement et de recherche français ou étrangers, des laboratoires publics ou privés.

\section{(ㅇ)(1) $\$$}

Distributed under a Creative Commons Attribution - NonCommerciall 4.0 International 
Version of Record: https:/www.sciencedirect.com/science/article/pii/S0016508518354179

Manuscript_e580b09f688e55f3edbef87bacc46b20

MNGIE natural history

\section{MyoNeuroGastroIntestinal Encephalopathy: natural history and means for early}

\section{diagnosis}

Giovanni Corazza ${ }^{1}$, Cécile Pagan ${ }^{2}$, Gaëlle Hardy ${ }^{1}$, Gérard Besson ${ }^{1}$, Anne Lombès ${ }^{3 *}$ and the investigators of the MNGIE project

\section{List of the investigators of the MNGIE project:}

David Seguy CHU Lille Nutrition Unit, F-59037 Lille France; Cécile Acquaviva-Bourdain and Francoise Bouhour Hospices Civils de Lyon Groupement Hospitalier Est Centre de Biologie et Pathologie Est, F-69677 Bron France; Pauline Gaignard and Abdelhamid Slama AP-HP, CHU Bicêtre Biochemistry department, F-94275 Le Kremlin-Bicêtre France; Agathe Roubertie and Raul Juntas Morales CHU Montpellier Neurology department, Institut des Neurosciences de Montpellier, INSERM U 1051, F-34295 Montpellier France; Magalie Barth CHU Angers Genetics department, F-49933 Angers France; Pascal Cintas CHU Toulouse Neurology department, F-31059 Toulouse France; Matthieu Bereau CHU Besançon Neurology department, F-25030 Besançon France; Emmanuelle Campana-Salort CHU Marseille Neurology department, F-13005 Marseille France; Hélène Ogier de Baulny, Manuel Schiff and Jean-François Benoist AP-HP CHU Robert Debré Reference Center for Inborn Errors of Metabolism, F-75019 Paris France; Christelle Corne CHU Grenoble-Alpes, F-38000 Grenoble France; Francisca Joly AP-HP CHU Beaujon Gastroenterology IBD and Nutrition Support department, F-92118 Clichy France.

${ }^{1}$ CHU Grenoble-Alpes, F-38000 Grenoble, France

${ }^{2}$ CHU Lyon, Groupement Hospitalier Est, Centre de biologie et Pathologie Est, F-69500 Bron, France

${ }^{3}$ INSERM U1016 ; CNRS UMR 8104 ; Université Paris 5 ; F-75014 Paris France 
Correspondence: Dr Anne Lombès, MD, PhD

Institut Cochin, Faculté de médecine, room 3011, 24 rue du Fb St Jacques, 75014 Paris,

France

Tel: +33153732753 - Fax: +331537327

Email: anne.lombes@inserm.fr

Word count: Title: 85 characters spaces included; Manuscript: 997 words

Grant support: This work was supported by grants from the Association Française contre les Myopathies (AFM) to AL and Association contre les Maladies Mitochondriales (AMMi) to AL.

Abbreviations: BMI: body mass index; MNGIE: MyoNeuroGastroIntestinal Encephalopathy; TP: thymidine phosphorylase;

Disclosures : The authors have no conflict to disclose.

Acknowledgement: The authors thank Prof Kevin M Flanigan, The Ohio State University College of Medicine, for his careful editing of the manuscript

\section{Author contributions}

Giovanni Corazza: study concept and design; acquisition of data; analysis and interpretation of data; drafting of the manuscript 
Cécile Pagan: acquisition of data; analysis and interpretation of data; critical revision of the manuscript

Gaëlle Hardy: acquisition of data; analysis and interpretation of data; critical revision of the manuscript

Gérard Besson: study concept and design; acquisition of data; analysis and interpretation of data; drafting of the manuscript; material support

Anne Lombès: study concept and design; acquisition of data; analysis and interpretation of data; critical revision of the manuscript; obtained funding; study supervision.

Keywords: Thymidine phosphorylase; Myo-Neuro-Intestinal Encephalopathy - MNGIE; Natural history 


\section{Introduction}

MyoNeuroGastroIntestinal Encephalopathy (MNGIE) is a rare multisystem mitochondrial disease, which predominantly presents with chronic intestinal signs (diarrhea, gastroparesis, recurrent vomiting, abdominal pain and bloating, pseudo-obstruction episodes) with associated neurological involvement (leukoencephalopathy, ophthalmoparesis, deafness, and demyelinating sensory motor peripheral neuropathy) ${ }^{1,2}$. Defective thymidine phosphorylase (TP), resulting from mutations in the TYMP gene, causes MNGIE via massive accumulation of thymidine and deoxyuridine that progressively alters mitochondrial DNA replication ${ }^{3}$. Several treatments have targeted this toxic accumulation. Hemodialysis, peritoneal dialysis, or platelet infusion resulted in only transient efficacy ${ }^{3}$. More lasting positive outcomes resulted from partial enzymatic restoration via TP encapsulated in erythrocytes ${ }^{4}$, liver transplantation ${ }^{5}$ or hematopoietic stem cells transplantation ${ }^{6}$. The latter had a very high mortality rate, with $15 / 24$ patients dying early during the procedure, most probably in relation to the cachexia constantly associated with MNGIE progression. In surviving patients, completely normalized thymidine/deoxyuridine levels accompanied long-term stabilization of the patients' clinical status. However, an absence of significant clinical recovery implied irreversibility of the intestinal and peripheral nerve damage. Early diagnosis of MNGIE, before severe tissue damage and cachexia, is therefore mandatory for treatment efficacy.

The sole previous report of a large cohort of MNGIE patients essentially described the clinical spectrum without addressing disease progression ${ }^{2}$. To address the barriers associated with diagnosis of MNGIE, we analyzed the natural history of all French MNGIE patients.

\section{Methods}

Every French patient with a diagnosis of MNGIE according to the criteria of $2004^{7}$ was included in this retrospective study. Two French laboratories provide TP assay for diagnosis; they recruited patients from 1999 to January 2018. There was no a priori exclusion criteria. 
The same investigator (GC) collected all clinical data by contacting the referring physician, the patient's general practitioner, and additional physicians when needed.

Collected data included gender, current age, family history (siblings and consanguinity), age at first specialized consultation in relation to MNGIE and at each follow-up, chief complaint at consultation, signs or symptoms and the age at their onset, physical examination, relevant laboratory data, electrophysiologic studies, and age at death when relevant. When available, Child Health Record booklets allowed establishing the patient's childhood growth curves.

\section{Results}

Twenty-eight patients had MNGIE diagnosed by the presence of a profound defect of TP activity and/or TYMP gene biallelic mutations (Supplemental Table 1). Insufficient information could be recovered for four patients who were already deceased; they were excluded from further analysis, resulting in a cohort of 24 patients from 21 independent families.

The main patient characteristics were remarkably similar to those in the previously reported MNGIE cohort ${ }^{2}$ (Supplemental Table 2). The French cohort was therefore representative of MNGIE, justifying its use to establish the natural history of the disease.

As shown in the Figure, comparison of the Kaplan-Meier survival curve (A) with that of the probability to remained undiagnosed (B) shows that diagnosis preceded death by only a few years, and that gastrointestinal complaints had an earlier onset than neurological signs, ophthalmoparesis, or deafness (C). The patients' median body mass index (BMI) at the first specialized medical consultation (at an average 25 years of age) was 14.5 , confirming the early onset of gastrointestinal signs. BMI appeared as a sensitive early marker based on the Child Health Record booklet, available for 10 patients. It was close to the third centile before 10 years of age for 6/9 patients while weight curves showed progressively blunted growth and 
height curves remained within the normal range, in accordance with the normal height observed for all adult MNGIE patients (Supplemental Figure).

Except for two patients with siblings previously diagnosed as MNGIE, all MNGIE patients had several alternative diagnoses made, leading to a median delay of 6 years (range $0-23$ ) between their first specialized medical consultation and the definitive diagnosis. The most frequent was anorexia nervosa, a diagnosis assigned to $41 \%$ of all patients, and $58 \%$ of women. The next most common was chronic inflammatory gastrointestinal disease, including Crohn's disease (in 33\%), coeliac disease (22\%), and esophagitis and/or gastritis (17\%), which led to unnecessary diagnostic procedures, including esophagogastroduodenoscopy (14 patients), intestinal biopsies (16 patients), and CT scans (8 patients). Similarly, the occurrence of neurological signs led to diagnoses of Charcot-Marie-Tooth disease (42\%), metabolic disorder (42\%), or acute or chronic polyradiculoneuritis (29\%). Electroneuromyography showing demyelinating neuropathy (19/21 patients) and/or brain imaging showing diffuse leukoencephalopathy (20/21 patients) were then major triggers for MNGIE diagnosis.

\section{Discussion}

Partial enzymatic restoration completely cures toxic accumulation causing MNGIE. However, early diagnosis, prior to the development of cachexia and irreversible tissue damage, is mandatory to ensure clinical benefit. With a goal of improving early diagnosis of MNGIE, we analyzed the natural history of all French MNGIE patients. Despite its retrospective nature, we believe that the overview of the MNGIE diagnostic process is accurate because we obtained $92 \%$ for the information being sought.

Consistent with the initial signs being gastro-intestinal, the first specialized medical consultation was in Gastroenterology (63\%) or Pediatrics $(21 \%)$ but rarely in Neurology (13\%). These signs lacked specificity and led to numerous differential diagnoses, all more frequent than MNGIE and several without specific diagnostic criteria, explaining their 
recurrent discussion. Neurologists made the diagnosis more often than gastroenterologists ( $56 \%$ versus $24 \%$ ) because signs in addition to intestinal troubles were major triggers for diagnosis. However, the delayed appearance of neurologic features means that cachexia often was already significant.

When suspected, the diagnosis of MNGIE is relatively easy because of the highly sensitive biochemical alterations. The TP assay is highly specific and easy to perform. Urinary organic acids chromatography showing peaks of thymine and uracile is suggestive. Molecular testing of TYMP gene is useful to confirm the diagnosis.

In conclusion, chronic intestinal troubles with a severe impact on BMI should prompt the clinician to consider TP deficiency and to order specific biochemical analyses. Although numerous negative results may be expected, the cost will be moderate and highly compensated for by the benefit for the rare MNGIE patients who, without early treatment, inexorably evolve towards severe cachexia, intestinal neuromyopathy and generalized polyneuropathy.

\section{Figure legends}

Kaplan-Meier curve of survival (A) and diagnosis (B); Natural history of MNGIE (C); Gastro=gastrointestinal symptoms (recurrent vomiting, chronic diarrhea, abdominal pain and bloating); Neuro=neurological symptoms (limb paresthesia, pain, sensory deficit or weakness); OPH = Ocular symptoms (ptosis and/or external ophthalmoplegia).

\section{References}

1. Hirano M, Silvestri G, Blake DM, et al. Mitochondrial neurogastrointestinal encephalomyopathy (MNGIE): clinical, biochemical, and genetic features of an autosomal recessive mitochondrial disorder. Neurology 1994;44:721-7.

2. Garone C, Tadesse S, Hirano M. Clinical and genetic spectrum of mitochondrial neurogastrointestinal encephalomyopathy. Brain 2011;134:3326-32. 
3. Spinazzola A, Marti R, Nishino I, et al. Altered thymidine metabolism due to defects of thymidine phosphorylase. J Biol Chem 2002;277:4128-33.

4. Bax BE, Bain MD, Scarpelli M, et al. Clinical and biochemical improvements in a patient with MNGIE following enzyme replacement. Neurology 2013;81:1269-71.

5. De Giorgio R, Pironi L, Rinaldi R, et al. Liver transplantation for mitochondrial neurogastrointestinal encephalomyopathy. Ann Neurol 2016;80:448-55.

6. Halter JP, Schupbach M, Mandel H et al. Allogeneic haematopoietic stem cell transplantation for mitochondrial neurogastrointestinal encephalomyopathy. Brain 2015;138:2847-58.

7. Marti R, Spinazzola A, Tadesse S, et al. Definitive diagnosis of mitochondrial neurogastrointestinal encephalomyopathy by biochemical assays. Clin Chem 2004;50:120-4.

Author names in bold designate shared co-first authorship 

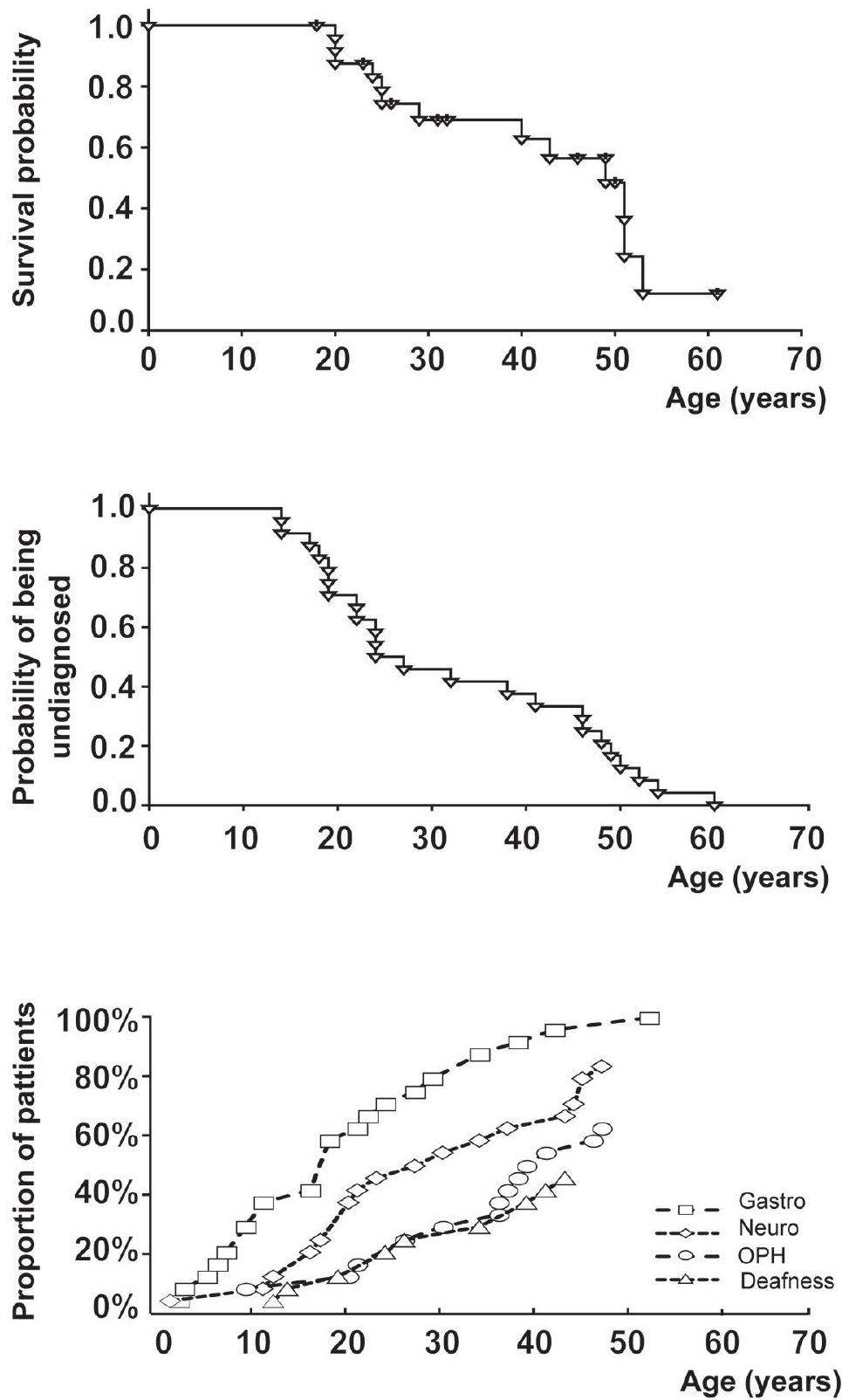